\title{
Scientific misconduct or criminal offence?
}

$\mathrm{W}$ hen is fraud not treated like fraud? When it falls under the euphemistic umbrella of scientific misconduct. That is the opinion, at least, of some members of the scientific community, who believe it is long past time that researchers who commit fraud in the lab face criminal charges in court.

"If you were a banker and defrauded your customers, you would go to prison," said Zulfiqar Bhutta, co-director of research for the Centre for Global Child Health at The Hospital for Sick Children in Toronto. "If someone defrauds tax payers with research money and falsifies data or falsifies entire research results, it is no different than any other form of similar economic crime."

Dr. Richard Smith, former editor of the British Medical Journal, made a similar argument in a recent blog post. He noted that some Volkswagen employees may be criminally charged for their involvement in the recent scandal over manipulating emissiontest results. And yet, for some reason, a scientist who "invents data, defrauds funders and publishes fabricated data that may lead to patient harm is highly unlikely to face criminal charges."

Not everyone agrees that criminalization is the answer. Treating research misconduct as a crime could have a chilling effect on science, one argument goes, and differentiating between deliberate fraud and general incompetence can be tough. Others say that scientific institutions are better suited to investigate allegations of research fraud than police. Bhutta, however, doesn't see it that way.

"Universities, research institutions and academic institutions generally don't have the stomach to go through this process," he said. "Very few want the kind of publicity that comes with research misconduct, which could affect funding."

In a 2014 BMJ article, Bhutta, who has a strong interest in research ethics, argued that scientific fraud can have

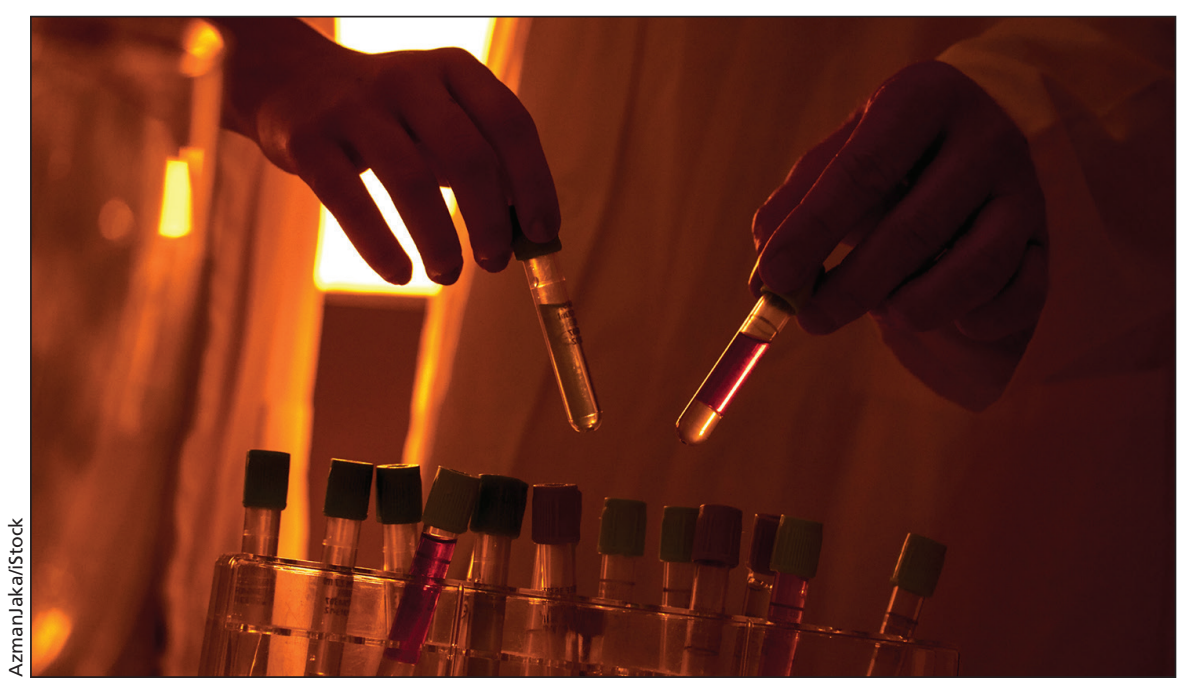

Should researchers who commit fraud in the lab face criminal charges in court?

huge consequences on public health and clinical practice, citing the damage to global vaccination coverage caused by the "fraudulent and discredited" research of Dr. Andrew Wakefield that linked vaccines to autism. There is little risk to committing research fraud, beyond damage to reputation, and the research community is doing an inadequate job of policing itself, according to Bhutta, who wrote that "additional deterrence through punitive measures such as criminal proceedings should be added to the repertoire of measures available."

Then again, perhaps devoting a lot of effort to imprisoning researchers wouldn't be the most effective or efficient way to improve science. "When you look at criminal offences, you can bring charges but you may not be able to meet the high standard of proof in a criminal case," said Susan Zimmerman, executive director of the Secretariat on Responsible Conduct of Research. "The amount of time and energy and resources that would go into attempting to prove a criminal conviction - and if you fail to meet that very high burden of proof, that person will get off."

The Secretariat is a government agency responsible for implementing the Tri-Agency Framework on Responsible Conduct of Research on behalf of Canada's major federal government granting agencies (the Canadian Institutes of Health Research, the Natural Sciences and Engineering Research Council and the Social Sciences and Humanities Research Council of Canada). A researcher who breeches the framework may receive letters of education or admonishment. More serious cases could merit sanctions, including withdrawal of funding or even the ability to apply for funding.

Each year, according to Zimmerman, there are about 90 breeches of the framework, but very few, perhaps three or four, would be considered serious. Even fewer would constitute a criminal offence. And if one did, the Secretariat is already obligated to notify the authorities. Instead of trying to ferret out the rare egregious bad apple, the Secretariat, as stewards of public money, focuses on reducing unacceptable results. The agency considers that approach to be a more productive use of limited resources than trying to determine if a researcher made an honest mistake or acted in bad faith.

"We are interested in ensuring the public record is correct and reliable and accurate, and we are interested in fixing your conduct if you are not doing that," said Zimmerman. "We are concerned if you lie on your application for funding. We are concerned if you mismanage 
your funds. We are concerned if, through incompetence or laziness or ignorance, you can't lay hands on accurate raw data."

As for how investigations into scientific misconduct could be improved at the university level, that can be summed up on one word: consistency. "Each university has its own policy for how it investigates research fraud and misconduct, and it's a real dog's breakfast," said David Robinson, executive director of the Canadian Association of University Teachers. "There should be some central office, like the Office of Research Integrity in the United States, that applies consistent rules across the country, and applies some transparency and accountability." — Roger Collier, CMAJ

CMAJ 2015. DOI:10.1503/cmaj.109-5171

\section{Can a new flu vaccine cure efficacy woes?}

$\mathrm{N}$ ew influenza vaccines that for the first time protect against four strains of the virus will be widely available across Canada this year.

Each year, the World Health Organization predicts which strains are likely to dominate during flu season and drug companies make vaccines to match. For decades, these vaccines covered only three strains of influenza: two A subtypes and one B subtype. But since the 1980s, the influenza B virus has split into two distinct lineages making it harder to match. Between 2001 and 2013, seasonal flu vaccines covered the wrong B virus 7 out of 12 times.

New four-strain vaccines, which protect against an additional influenza $B$ subtype, may provide broader protection. "The strains of influenza that are circulating keep changing their coats, or the buttons on their coats, and a quadrivalent vaccine gives us more chances to match these changes," explains Dr. Noni MacDonald, an infectious disease expert and professor of pediatrics at Dalhousie University in Halifax.

The consequences of a poor match can be serious. The Public Health Agency of Canada estimates up to a quarter of hospital admissions and deaths are attributable to influenza B in any given season.

Quadrivalent flu vaccines were licensed in Canada last year, but this season will be the first time the new vaccines are widely used in public immunization programs. Provinces and territories have ordered about 12 million doses of flu vaccine, 2.9 million of which will be four-strain products.

Some jurisdictions, including Manitoba, the Atlantic provinces and the Yukon, will provide quadrivalent vaccines to all residents aged six months and older. Other public immunization programs, including those in Alberta

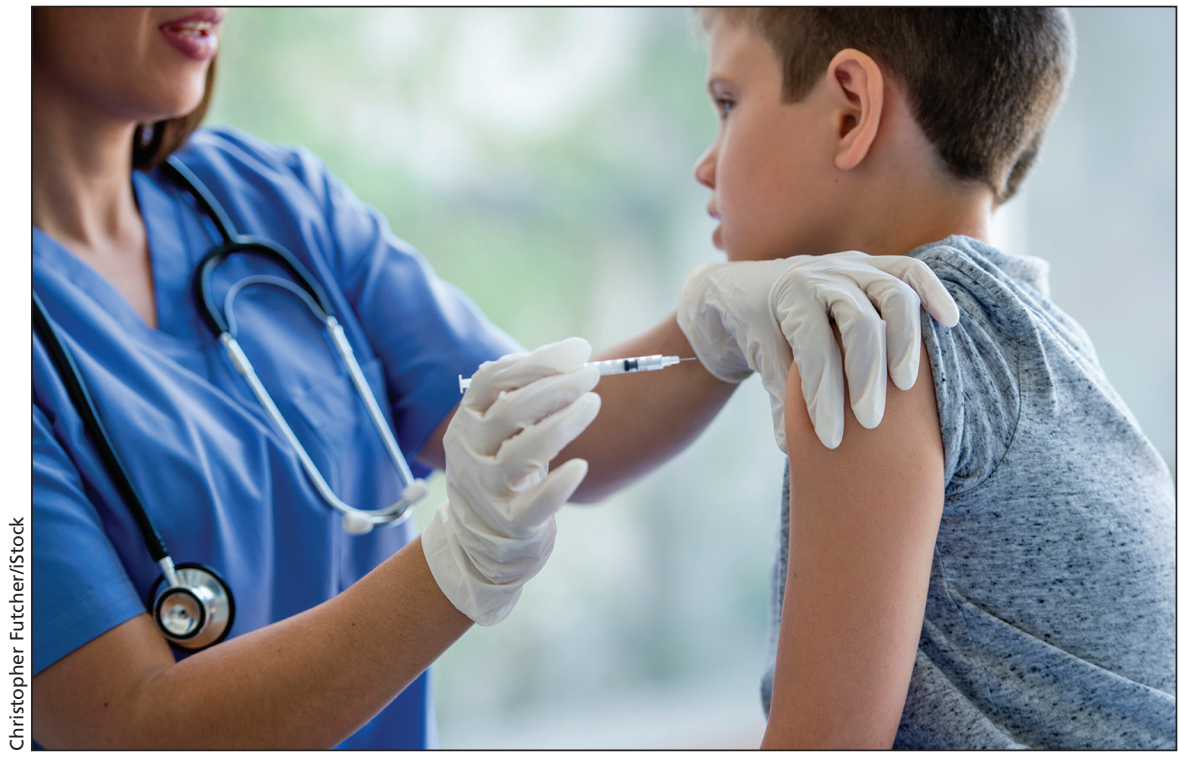

Canadians have a new weapon in their anti-flu arsenal this season.

and Ontario, will only provide fourstrain vaccines to children aged 6 months to 17 years. Most adults will continue to receive three-strain products.

"This mix of vaccines gives us a cost-efficient way to target the right levels of protection for our most vulnerable citizens," says Carolyn Ziegler, a spokesperson for Alberta Health.

The sticker price of quadrivalent flu vaccines can be 1.5 times higher than for trivalent products, but governments often negotiate lower prices with manufacturers behind closed doors. Studies also indicate that four-strain vaccines may still be more cost-effective overall, even at a higher price per dose, because of the broader protection they provide.

According to Canada's National Advisory Committee, both quadrivalent and trivalent flu vaccines are acceptable choices for adults, although children should receive four-strain products when available.

This recommendation is partly based on an expectation that adults will have some cross-protection from previous exposures to influenza B, says Dr. Dion Neame, senior director of scientific and medical affairs for vaccine manufacturer Sanofi Pasteur.

MacDonald notes that availability of a vaccine can influence recommendations. For example, the United States Centers for Disease Control and Prevention haven't favoured quadrivalent vaccines over three-strain products partly because they don't want people to miss getting the flu shot while waiting for access to a limited supply.

Receiving the trivalent vaccine, even in seasons when it is less than $23 \%$ effective, is still better than nothing, MacDonald notes. "Year after year, data from many different countries and many different settings show that people who get vaccinated have lower morbidity and mortality, particularly among the elderly and hospitalized kids." - Lauren Vogel, CMAJ

CMAJ 2015. DOI:10.1503/cmaj.109-5179 